\title{
Can coffee consumption be used to accelerate the recovery of bowel function after cesarean section? Randomized prospective trial
}

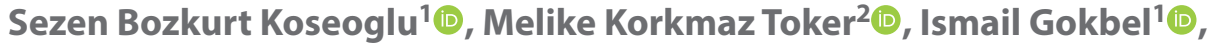 \\ Ozgu Celikkol'미, Kemal Gungorduk ${ }^{1}$ (1) \\ ${ }^{1}$ Mugla Sıtkı Kocman University, Training and Research Hospital, Department of Gynecology and Obstetrics, Turkey \\ ${ }^{2}$ Mugla Sıtkı Kocman University, Training and Research Hospital, Department of Anesthesiology and Reanimation, Turkey
}

\begin{abstract}
:
Objectives: To evaluate whether coffee consumption accelerates the recovery of bowel function after cesarean section or not. Material and methods: This study was designed as randomized controlled study. Patients were randomly assigned to one of two groups: Ultimately, Group $1(n=51)$ was the study group and drank three cups of coffee after cesarean, whereas group 2 ( $n=52$ ) was not given any treatment. The primary outcome measure was the time to first defecation after surgery, the secondary outcomes were time to first bowel movement, passage of flatus, time to toleration of a solid diet, additional antiemetic and analgesic requirement.

Results: There were no significant differences in demographic variables between the groups. The mean time to passage of first flatus was significantly shorter in the study group than the control group ( $8.6 \pm 3.3 \mathrm{~h}$ vs $11.3 \pm 7.5 \mathrm{~h}$, respectively; $p=0.022$ ). First defecation was $20.7 \pm 11.5 \mathrm{~h}$ for the study group and at $29.1 \pm 14.3 \mathrm{~h}$ for the control group ( $p=0.001)$. In addition, there was a significant difference in mean time to toleration of solid food between the study and control groups $(8.78 \pm 2.33 \mathrm{~h}$ vs $12.88 \pm 4.2 .60 \mathrm{~h}$, respectively; $\mathrm{p}<0.001)$.

Conclusions: Coffee can be used in patients to enhance the recovery of gastrointestinal function after elective cesarean section.
\end{abstract}

Key words: caffeine; coffee; ileus; cesarean section

\section{INTRODUCTION}

Cesarean section has become the most common type of obstetric surgery worldwide. As the postcesarean period coincides with breastfeeding and caring for the infant, appropriate postoperation follow-up is necessary to help not only the patient but also the baby. Postoperative ileus (POI) is a common complaint after cesarean section because gastric emptying is delayed in pregnancy, especially during labor. POl is a transient cessation of bowel function and a major contributing factor to postoperative discomfort [1]. Clinically, $\mathrm{POI}$ is characterized by abdominal distension, a lack of bowel sounds, nausea, vomiting, stomach cramps, and lack of flatus [2]. POI leads to prolonged hospital stays, and reduces patient satisfaction after surgery, especially after cesarean section, due to the delay in mother-baby bonding $[3,4]$.
Rapid recovery following cesarean section is important for both the baby and mother. Furthermore, POI is associated with costs of between $\$ 5000$ and $\$ 10000$ in the USA, for an annual total of $\$ 1$ billion because of prolonged hospital stays and high treatment costs. Therefore, it is important to find a safe method to reduce POI. Many clinical methods have been attempted to reduce POI, including early feeding, fluid restriction, gum chewing, preoperative carbohydrate loading, and epidural analgesia [5-12]. However, none of these have been completely successful in the prevention of POI.

Coffee is a popular beverage world wide and improves general prosperity. In addition, it has positive effects on the central nervous, cardiovascular, and reproductive systems [13]. Coffee is known to trigger the gastrointestinal motor activity 
in participants with no concomitant diseases $[14,15]$. There is constrained logical proof in regards to its consequences for gastrointestinal capacity. Two reports proposed that coffee consumption after both open and laparoscopic colectomy is sheltered and is related with diminished duration to the initiation of bowel activity $[16,17]$. It is also known that coffee accelerates bowel function after malignant gynecological surgery [18]. However, a methodical survey of PubMed, OvidSP, Google Scholar, and Scopus recognized just a single past examination of its impacts on gastrointestinal behaviour in patients after cesarean section [19]. Unfortunately, this study was not within Enhanced Recovery After Surgery (ERAS) Guidelines according to which early feeding is essential for patients undergoing surgery [20].

\section{Objectives}

Consequently, we carried out a randomized controlled trial to evaluate even if coffee consumption stimulates the recovery of bowel function after cesarean section in in concurrence with ERAS guidelines.

\section{MATERIAL AND METHODS}

This randomized controlled study was carried out at Mugla Sitki Kocman University Training and Research Hospital, Department of Obstetrics and Gynecology, from 30th October 2018 to $1^{\text {st }}$ March 2019. After obtaining institutional research and ethics approval, 110 pregnant women with elective cesarean section were included in the study (Reference number: $2017,13 / 4)$. The study was designed in accordance with the tenets of the Declaration of Helsinki and was registered with anzctr.org.au (ACTRN12618001772235).

The inclusion criteria were women aged between 18 and 35 years, with no allergy to coffee, and undergoing spinal anesthesia. The exclusion criteria were emergency cesarean, cesarean with general anesthesia, history of previous pelvic or abdominal surgery (excluding previous cesarean section), chronic constipation, any known thyroid disease, irritable bowel syndrome, and any known hypersensitivity or allergy to caffeine. The patients were also excluded if their surgery lasted more than 60 minutes. The objectives of the trial were described to the patients, and written informed consent was received from all participants before enrollment. Blinding could not be performed due to the timing of utilization of the assigned intervention except for observers and outcome assessors.

Patients were hospitalized on the day of surgery. Patients were randomly assigned in a 1:1 ratio either group $A$ or group B when they were admitted to our clinic. Permuted-block randomization, with concealed varying block sizes of two, four, or six, was performed centrally via an online module using a computer-generated randomization sequence. Group A served as the study group and drank three cups of coffee daily beginning from 2 hours after surgery, whereas group B was not given any treatment. As the standard clinical protocol, patients were not allowed to receive solid or liquid food 8 hours before surgery. An oral or mechanical bowel preparation was not used prior to surgery.

All patients underwent the same anesthetic protocol. Each patient received intravenous (IV) volume preloading with $15 \mathrm{~mL} / \mathrm{kg}$ of $0.9 \%$ saline within $25 \mathrm{~min}$ before entering the operating room. After the patients arrived at the operating room, standard monitoring procedures consistent with American Society of Anesthesiologists guidelines were applied. A subarachnoid block was performed with the patients in the sitting position at the L3-4 interspaces using $2 \mathrm{~mL}$ ( $10 \mathrm{mg}$ ) of hyperbaric bupivacaine plus $10 \mu \mathrm{g}$ of fentanyl with a 25-gauge Quincke spinal needle (Egemen International, Izmir, Turkey). The patients were repositioned in the supine position with a left lateral tilt and supplemental oxygen was delivered at a rate of $4 \mathrm{~L} / \mathrm{min}$ via a face mask. In addition intraoperative antiemetic agents $(0.05 \mathrm{mg} / \mathrm{kg}$ ondansetron and $0.1 \mathrm{mg} / \mathrm{kg}$ dexamethasone) were used prophylactically. All cesarean sections were performed by the same surgical team using the Pfannenstiel incision on the abdomen and transverse lower uterine incision. The duration of surgery was defined as the time from the onset of surgery to skin closure.

The patients in the study group drank $100 \mathrm{~mL}$ of caffeinated coffee without sugar or milk provided by a nurse or doctor at 2, 6, and 18 hours after surgery (Nescafe ${ }^{\circledR}, 2 \mathrm{~g}$, $100 \mathrm{mg}$ of caffeine). All women drank coffee completely. Patients were allowed to drink any measure of water without coffee, black tea, or other type of caffeinated drink. According to our post-cesarean care protocol, the patients received Ringer's lactate associated with 30 IU of oxytocin and and analgesic agent ( $75 \mathrm{mg}$ of intramuscular diclofenac sodium, $2 \mathrm{x}$ in 1 day if not contraindicated). The need for extra analgesic and other medications, including antiemetics, was recorded. No oral or rectal intestinal stimulants were used after cesarean section.

Early breastfeeding and ambulation were encouraged in both groups. All patients were mobilized after performing a sitting position for 5 minutes in bed, beginning from 6 hours after surgery, for approximately 10-15 minutes. Hemoglobin levels were checked 6 and 24 hours after surgery by a complete blood count, and the results were recorded. The weight and sex of the newborn infants were also recorded after birth.

The outlined primary outcome measure was the time to first defecation after surgery (measured from the end of surgery). The secondary outcomes were time to first bowel movement (measured from the end of surgery), first passage of flatus, time to toleration of a solid diet (measured from the end of surgery), additional antiemetic [metoclo- 
pramide, $10 \mathrm{mg}$ (Primperan ${ }^{\oplus}$; Sanovi Aventis, Paris, France)] need, and additional analgesic requirement. Time to first bowel movement was defined as when the patient noticed the first bowel sound or movement.

To correctly observe the return of bowel function, participants were advised to warn nurses or researchers immediately after the first passage of flatus or a bowel movement and defecation. We examined bowel movements by auscultation eight times per day starting 24 hours postoperatively until the first bowel sounds were noted. The postoperative nutrition was regulated; a liquid diet was commenced two hours after cesarean section and advanced to a regular diet within the four hours. Postoperative ileus was described as a narrow mindedness to oral nourishment without clinical or radiological indications of obstruction, that either a) requires nasogastric tube insertion; or b) was related with two of the accompanying: nausea/vomiting, stomach distension, and the nonattendance of flatus hours on or after postoperative day two [21].

The symptoms and signs of ileus were evaluated six times daily by an investigator who was blinded to the study allocation. Discharge criteria from the hospital included tolerance of a regular diet, absence of fever or signs of surgical site infection, ambulating at baseline; and passage of flatus or stool. Consistent with our ministry of health protocol, the patients were not discharged from the hospital before 48 hours after cesarean section.

All trials reported to date that had explored coffee intake had included only patients who had undergone colonic surgery or had a gynecologic malignancy. Therefore, we ran a pilot trial with 20 patients in each group (A-coffee and $\mathrm{B}$-control) before the full study. The mean time to first defecation was $23.6 \pm 13.7 \mathrm{~h}$ in group $A$ and $31.7 \pm 6.5 \mathrm{~h}$ in group B. Based on these data, we calculated that, to attain a study power of $90 \%$ with an a level of $0.05,50$ patients were required in each group. Assuming a $10 \%$ dropout rate, 110 patients were required. These patients were included the study.

Statistical analyses were performed using Med Calc (version 16.4; Med Calc Software, Ostend, Belgium). Normality of the variables was examined using the Kolmogorov-Smirnov test. The chi-square and Fisher's tests were used to compare categorical variables, Student's t-test was used to compare normally distributed continuous variables, and the Mann-Whitney $U$ test was used to compare variables that were not normally distributed. We used an intention-totreat protocol. In all analyses, $\mathrm{p}<0.05$ was taken to indicate statistical significance.

\section{RESULTS}

A total of 110 patients were enrolled in the study. Before randomization, two patients were excluded because they no longer fulfilled the inclusion criteria and refused to participate. Overall, 53 patients were assigned randomly to the study group and 55 were assigned to the control group. Ultimately, the conditions of 52 patients in the control group and 51 in the study group were analyzed. The reasons for exclusion after randomization are shown in Figure 1. Demographic information of the patients is presented in Table 1. There were no significant differences in demographic variables between the two groups. The indications for cesarean section in both the coffee and control groups are shown in Table 2. The most frequent cesarean indication was "previous cesarean" for both the study and control groups. The mean operation duration in the study group was $43.43 \pm 7.51 \mathrm{~min}$. while that in the control group was $44.25 \pm 7.97 \mathrm{~min}$. $(p=0.636)$.

Similar to the mean operation duration, there was no significant difference in size of incision between the study and control groups $(900.98 \pm 0.73 \mathrm{~mm}$ vs $100.0 \pm 0.79 \mathrm{~mm}$, respectively; $\mathrm{p}=0.897$ ).

Table 3 shows the data for return of bowel function between the two groups. There was no significant difference in time to first bowel sound between the study and control groups $(5.7 \pm 3.5$ h vs $6.4 \pm 2.6 \mathrm{~h}$, respectively; $p=0.316$ ), but the time to passage of first flatus was significantly shorter in the study group than in the control group ( $8.6 \pm 3.3 \mathrm{~h}$ vs $11.3 \pm 7.5 \mathrm{~h}$, respectively; $\mathrm{p}=0.022$ ). First defecation was recorded at $20.7 \pm 11.5 \mathrm{~h}$ for the study group and at $29.1 \pm 14.3 \mathrm{~h}$ for the control group $(p=0.001)$. In addition, there was a significant difference in mean time to toleration of solid food between the study and control groups $(8.78 \pm 2.33 \mathrm{~h}$ vs $12.88 \pm 2.60 \mathrm{~h}$, respectively; $\mathrm{p}<0.001)$

A total of 13 patients ( $25.5 \%)$ in the study group and $23(44.2 \%)$ in the control group required additional analgesics $(p=0.046)$. And also 5 patients $(9.8 \%)$ in the study group and 13 patients (25\%) in the control group required additional antiemetic $(p=0.042)$. There was a significant difference in antiemetic and analgesic requirement between the groups (Tab. 3). There were no symptoms of ileus in any of the patients, and all patients were discharged $48 \mathrm{~h}$ postoperatively with no complications.

\section{DISCUSSION}

This randomized controlled study indicates that drinking coffee early in the postoperative period after cesarean section reduced the mean times to first flatus, defecation, and toleration of solid food. The mean time to the first bowel sound was shorter in the study group than in the control group, but the difference was not significant. To our knowledge, this is the first study to evaluate the effects of early coffee consumption on the recovery of bowel function after cesarean section. 


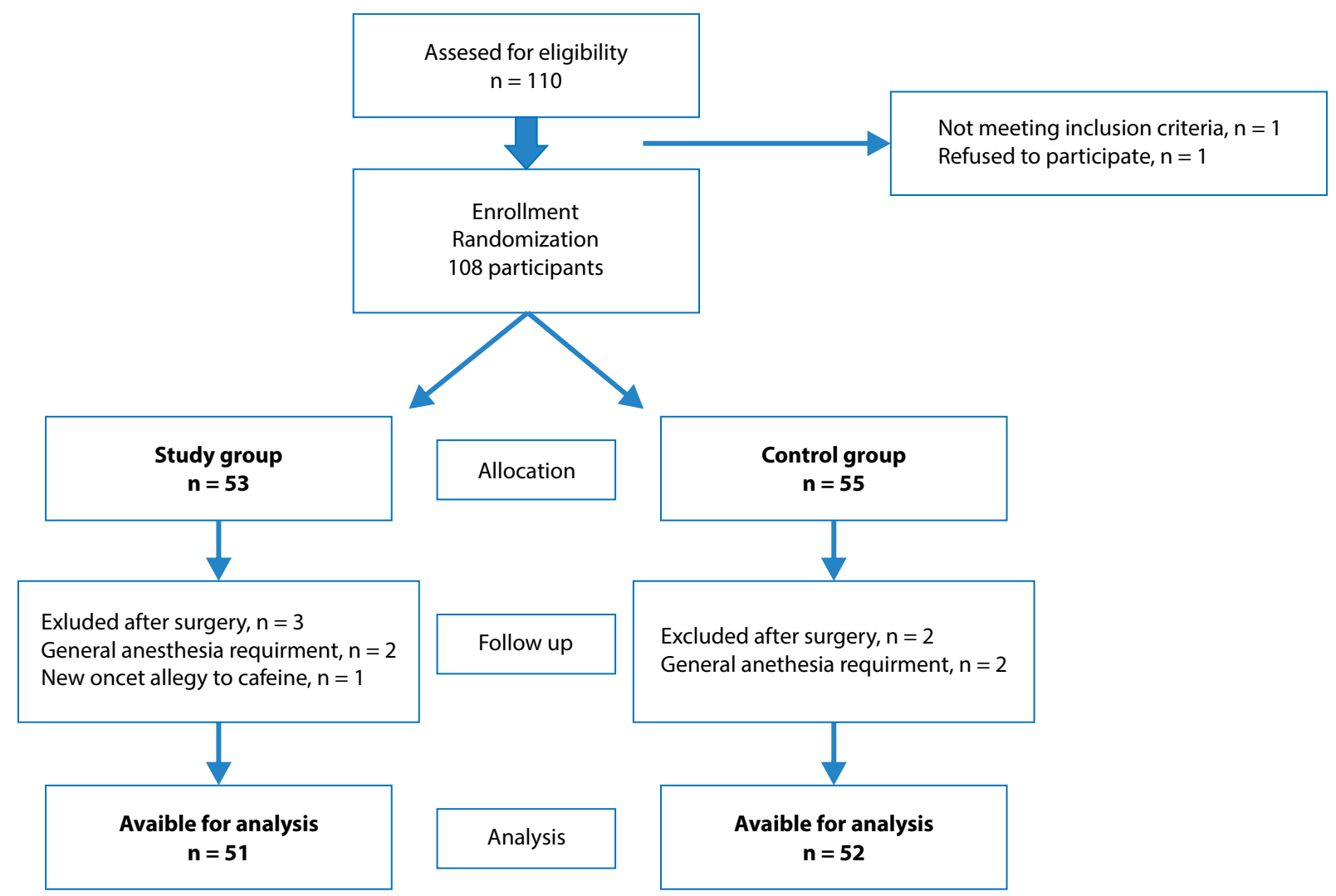

Figure 1. Flow diagram of trial recruitment and follow-up

\begin{tabular}{|l|l|l|l|}
\hline \multicolumn{4}{|l|}{ Table 1. Baseline characteristics of the patients } \\
\hline & $\begin{array}{l}\text { Study group } \\
\text { (n=51) }\end{array}$ & $\begin{array}{l}\text { Control group } \\
\text { (n=52) }\end{array}$ & P-value \\
\hline Age [years]* & $28.70 \pm 5.42$ & $29.25 \pm 5.74$ & 0.622 \\
\hline Gravida* & $2.5 \pm 1.0$ & $2.2 \pm 1.0$ & 0.283 \\
\hline Parity* & $1.33 \pm 1.01$ & $1.23 \pm 1.23$ & 0.607 \\
\hline $\begin{array}{l}\text { Number of prior } \\
\text { ceserean section** }\end{array}$ & $38(80.8)$ & $39(90.7)$ & \\
\hline 1 & $7(14.8)$ & $3(6.9)$ & \\
\hline $\begin{array}{l}\text { 2 } \\
\text { 3 }\end{array}$ & $1(2.2)$ & $1(2.4)$ & \\
\hline 4 & $1(2.2)$ & - & \\
\hline Smoking** & $1(1.9)$ & $2(3.8)$ & 1.0 \\
\hline Alcohol** & 0 & 0 & NA \\
\hline Hypertension** & $3(5.8)$ & $1(0)$ & 0.298 \\
\hline $\begin{array}{l}\text { Gestational diabetes } \\
\text { mellitus** }\end{array}$ & $2(3.9)$ & $1(0)$ & 0.546 \\
\hline
\end{tabular}

*Values are given as the mean \pm standard deviation

**Values are given as the number (percentage)

The pathogenesis of ileus has not been completely elucidated, and it seems to be multifactorial in nature. lleus may be due to an inflammatory process related to surgical manipulation of the intestine during surgery that leads to significant leukocyte infiltration of the muscular layer

\begin{tabular}{|c|c|c|c|}
\hline & $\begin{array}{l}\text { Study group } \\
(n=51)\end{array}$ & $\begin{array}{l}\text { Control group } \\
(n=52)\end{array}$ & P-value \\
\hline \multicolumn{4}{|c|}{ Indication for cesarean section } \\
\hline $\begin{array}{l}\text { Previous } \\
\text { ceserean section }^{* *}\end{array}$ & $47(92.1)$ & $43(82.6)$ & \multirow{5}{*}{0.206} \\
\hline $\begin{array}{l}\text { Fetal } \\
\text { macrosomia** }\end{array}$ & $2(3.9)$ & $2(3.8)$ & \\
\hline $\begin{array}{l}\text { Cephalopelvic } \\
\text { disproportion ** }\end{array}$ & $1(2)$ & $3(5.8)$ & \\
\hline $\begin{array}{l}\text { Breech } \\
\text { presentation }^{* *}\end{array}$ & $0(0)$ & $4(7.8)$ & \\
\hline Twin pregnancy ${ }^{* *}$ & $1(2)$ & $0(0)$ & \\
\hline $\begin{array}{l}\text { Operation duration } \\
\text { [minutes]* }\end{array}$ & $43.43 \pm 7.51$ & $44.25 \pm 7.97$ & 0.636 \\
\hline $\begin{array}{l}\text { Incision size } \\
\text { [millimeter] }\end{array}$ & $900.98 \pm 0.73$ & $100.0 \pm 0.79$ & 0.897 \\
\hline $\begin{array}{l}\text { Birth weight of } \\
\text { fetuses [gram]* }\end{array}$ & $3628.43 \pm 485.00$ & $3489 \pm 492.15$ & 0.152 \\
\hline $\begin{array}{l}\text { Sex of fetus }{ }^{* *} \\
\text { Male } \\
\text { Female }\end{array}$ & $\begin{array}{l}24(47) \\
27(53)\end{array}$ & $\begin{array}{l}28(53.8) \\
24(46.2)\end{array}$ & 0.491 \\
\hline $\begin{array}{l}\text { Decrease } \\
\text { hemoglobin level } \\
\text { [gram/deciliter]* }\end{array}$ & $1.49 \pm 0.41$ & $1.45 \pm 1.37$ & 0.622 \\
\hline
\end{tabular}

*Values are given as the mean \pm standard deviation

**Values are given as the number (percentage) 


\begin{tabular}{|c|c|c|c|}
\hline & $\begin{array}{l}\text { Study group } \\
(n=51)\end{array}$ & $\begin{array}{l}\text { Control group } \\
(n=52)\end{array}$ & p-value \\
\hline $\begin{array}{l}\text { Mean time to first } \\
\text { bowel movement } \\
\text { [hour] }\end{array}$ & $5.7 \pm 3.4^{*}$ & $6.4 \pm 2.7^{*}$ & 0.316 \\
\hline $\begin{array}{l}\text { Mean time to first } \\
\text { flatus [hour] }\end{array}$ & $8.6 \pm 3.3^{*}$ & $11.3 \pm 7.5^{*}$ & 0.022 \\
\hline $\begin{array}{l}\text { Mean time to first } \\
\text { defecation [hour] }\end{array}$ & $20.7 \pm 11.5^{*}$ & $29.1 \pm 14.3^{*}$ & 0.001 \\
\hline $\begin{array}{l}\text { Mean time to } \\
\text { toleration of solid } \\
\text { food [hour] }\end{array}$ & $8.78 \pm 2.33 *$ & $12.88 \pm 2.60^{*}$ & $<0.001$ \\
\hline Postoperative ileus** & - & - & NS \\
\hline $\begin{array}{l}\text { Additional analgesic } \\
\text { requirement** }\end{array}$ & $13(25.5)$ & $23(44.2)$ & 0.046 \\
\hline $\begin{array}{l}\text { Additional } \\
\text { antiemetic } \\
\text { requirement }{ }^{* *}\end{array}$ & $5(9.8)$ & $13(25)$ & 0.042 \\
\hline
\end{tabular}

of the intestine and intensive induction of inducible nitric oxide synthase [22].

There are reports in the literature with conflicting results regarding the effects of coffee on bowel function after gastrointestinal surgery. The first randomized controlled trial noted improved gastrointestinal function in patients drinking coffee without worsening of postoperative morbidity. This study was performed in 2012 by Müller et al. and included patients with malign and benign disease undergoing open or laparoscopic colectomy [16]. Müller reported shorter first bowel movement times in the coffee group, however the times to first flatus and tolerance of solid food were similar between groups. In contrast, Dulskas et al. reported diminished times to the first bowel movement and tolerance of solid food with decaffeinated coffee compared to caffeinated coffee and suggested that caffeine is not the main ingredient affecting bowel function [17]. Gungorduk et al. reported significant differences in the mean times to first flatus, first defecation, and toleration of solid food in the coffee drinking group among 114 patients undergoing surgery for gynecological malignancies [18]. In these three studies of patients following gastrointestinal or oncological surgery, coffee was given on the morning after surgery. There has been only one randomized controlled trial about the effects of coffee consumption on bowel function after cesarean section; in their study, Rabiepoor et al. started coffee consumption at 8 hours postoperatively, which is different from the present study [19]. They reported mean times to first flatus of 17.28 hours in the coffee group and 22.54 hours in the control group. This study has some limitations. Early postoperative feeding was not used in that study and oral feeding was started 24 hours after the operation. However, early feeding is recommended even in gynecological surgeries for malignant disease to decrease the hospitalization time and prevent POI risk [23]. Although cesarean section is a minor operation compared to gynecological malignancy operations, early mobilization and feeding may result in early recovery and have positive effects on breastfeeding. In addition, early time to toleration of solid food is important after cesarean section to facilitate breastfeeding. Also, in the study by Rabiepoor et al., data regarding time to toleration of solid food as well as additional analgesic and antiemetic requirements were not mentioned [19]. There was also no information regarding patient mobilization. Prolonged bedrest may enhance the risk of postoperative complications and prolong recovery $[24,25]$.

The main result of the present study is that the time for return of bowel function was shorter in the coffee drinking group. In previous studies, both groups of patients underwent major surgery and coffee consumption started later. In the present study, we started coffee consumption in the early postoperative period and provided early mobilization, so the mean times to first flatus, first defecation, and bowel movements were shorter than in previous reports. A number of factors, including blood loss, blood transfusion, advanced age, and increased incision size, were shown to be related to POI [26-29]. In the present study, all of these factors were similar between the two groups.

Our study has several strengths. First, it was a prospective randomized trial and the patient characteristics were similar between the two groups. Moreover, the study was performed at a single institution with the same surgical team and the same anesthetic protocol, which likely increased the validity of our results. Unfortunately, this study also has several limitations. First, blinding of the subjects postoperatively was not possible due to the nature of the study protocol. Secondly, we did not have placebo and decaffeinated control groups.

\section{CONCLUSIONS}

In conclusion, our results suggest that early coffee consumption following cesarean section contributes to the stimulation of bowel motility. Coffee is a safe, inexpensive, and welltolerated beverage, and it can be used in patients to enhance the recovery of gastrointestinal function after elective cesarean section.

\section{Ethical approval}

All procedures performed in studies involving human participants were in accordance with the ethical standards of the institutional and national research committee and with the 1964 Helsinki declaration and its later amendments or comparable ethical standards. 


\section{Informed consent}

Informed consent was obtained from all individual participants included in the study.

\section{REFERENCES}

1. Delaney CP. Clinical perspective on postoperative ileus and the effect of opiates. Neurogastroenterol Motil. 2004; 16 Suppl 2: 61-66, doi: 10.1111/j.1743-3150.2004.00559.x, indexed in Pubmed: 15357853.

2. Holte $\mathrm{K}$, Kehlet $\mathrm{H}$. Postoperative ileus: a preventable event. $\mathrm{Br} J$ Surg. 2000; 87(11): 1480-1493, doi: 10.1046/j.1365-2168.2000.01595.x, indexed in Pubmed: 11091234.

3. Asgeirsson T, El-Badawi Kl, Mahmood A, et al. Postoperative ileus: it costs more than you expect. J Am Coll Surg. 2010; 210(2): 228-231, doi: 10.1016/j.jamcollsurg.2009.09.028, indexed in Pubmed: 20113944.

4. Jakobsen DH, Sonne E, Andreasen J, et al. Convalescence after colonic surgery with fast-track vs conventional care. Colorectal Dis. 2006; 8(8): 683-687, doi: 10.1111/j.1463-1318.2006.00995.x, indexed in Pubmed: 16970579.

5. Fitzgerald JE, Ahmed I. Systematic review and meta-analysis of chewing-gum therapy in the reduction of postoperative paralytic ileus following gastrointestinal surgery. World J Surg. 2009; 33(12): 2557-2566, doi: 10.1007/s00268-009-0104-5, indexed in Pubmed: 19763686.

6. Teoh WHL, Shah MK, Mah CL. A randomised controlled trial on beneficial effects of early feeding post-Caesarean delivery under regional anaesthesia. Singapore Med J. 2007; 48(2): 152-157, indexed in Pubmed: 17304396.

7. Ogbadua AO, Agida TE, Akaba GO, et al. Early Versus Delayed Oral Feeding after Uncomplicated Cesarean Section under Spinal Anesthesia: A Randomized Controlled Trial. Niger J Surg. 2018; 24(1): 6-11, doi: 10.4103/njs.NJS_26_17, indexed in Pubmed: 29643726.

8. Wind J, Hofland J, Preckel B, et al. Perioperative strategy in colonic surgery; LAparoscopy and/or FAst track multimodal management versus standard care (LAFA trial). BMC Surg. 2006; 6: 16, doi: 10.1186/14712482-6-16, indexed in Pubmed: 17134506.

9. Holte K, Foss NB, Andersen J, et al. Liberal versus restrictive fluid management in knee arthroplasty: a randomized, double-blind study. Anesth Analg. 2007; 105(2): 465-474, doi: 10.1213/01.ane.0000263268.08222.19, indexed in Pubmed: 17646507.

10. Ajuzieogu OV, Amucheazi A, Ezike HA, et al. The efficacy of chewing gum on postoperative ileus following cesarean section in Enugu, South East Nigeria: A randomized controlled clinical trial. Niger J Clin Pract. 2014; 17(6): 739-742, doi: 10.4103/1119-3077.144388, indexed in Pubmed: 25385912.

11. Noblett $\mathrm{SE}$, Watson $\mathrm{DS}$, Huong $\mathrm{H}$, et al. Pre-operative oral carbohydrate loading in colorectal surgery: a randomized controlled trial. Colorectal Dis. 2006; 8(7): 563-569, doi: 10.1111/j.1463-1318.2006.00965.x, indexed in Pubmed: 16919107.

12. Zingg $U$, Miskovic $D$, Hamel $C T$, et al. Influence of thoracic epidural analgesia on postoperative pain relief and ileus after laparoscopic colorectal resection : Benefit with epidural analgesia. Surg Endosc. 2009; 23(2): 276-282, doi: 10.1007/s00464-008-9888-x, indexed in Pubmed: 18363059.

13. George SE, Ramalakshmi K, Mohan Rao LJ. A perception on health benefits of coffee. Crit Rev Food Sci Nutr. 2008; 48(5): 464-486, doi: 10.1080/10408390701522445, indexed in Pubmed: 18464035.

14. Brown SR, Cann PA, Read NW. Effect of coffee on distal colon function. Gut. 1990; 31(4): 450-453, doi: 10.1136/gut.31.4.450, indexed in Pubmed: 2338272.
15. Rao SS, Welcher K, Zimmerman B, et al. Is coffee a colonic stimulant? Eur J Gastroenterol Hepatol. 1998; 10(2): 113-118, doi: 10.1097/00042737199802000-00003, indexed in Pubmed: 9581985.

16. Müller SA, Rahbari NN, Schneider F, et al. Randomized clinical trial on the effect of coffee on postoperative ileus following elective colectomy. Br J Surg. 2012; 99(11): 1530-1538, doi: 10.1002/bjs.8885, indexed in Pubmed: 22987303.

17. Dulskas A, Klimovskij M, Vitkauskiene M, et al. Effect of Coffee on the Length of Postoperative Ileus After Elective Laparoscopic Left-Sided Colectomy: A Randomized, Prospective Single-Center Study. Dis Colon Rectum. 2015; 58(11): 1064-1069, doi: 10.1097/DCR.0000000000000449, indexed in Pubmed: 26445179.

18. GüngördükK, Özdemir IA, Güngördük Ö, et al. Effects of coffee consumption on gut recovery after surgery of gynecological cancer patients: a randomized controlled trial. Am J Obstet Gynecol. 2017; 216(2): 145.e1-145. e7, doi: 10.1016/j.ajog.2016.10.019, indexed in Pubmed: 27780709.

19. Rabiepoor S, Yas A, Navaei J, et al. Does coffee affect the bowel function after caesarean section? Eur J Obstet Gynecol Reprod Biol. 2018; 220: 96-99, doi: 10.1016/j.ejogrb.2017.07.028, indexed in Pubmed: 29202396.

20. Macones GA, Caughey AB, Wood SL, et al. Guidelines for postoperative care in cesarean delivery: Enhanced Recovery After Surgery (ERAS) Society recommendations (part 3). Am J Obstet Gynecol. 2019; 221(3): 247.e1-247.e9, doi: 10.1016/j.ajog.2019.04.012, indexed in Pubmed: 30995461.

21. Garfinkle R, Trabulsi N, Morin N, et al. Study protocol evaluating the use of bowel stimulation before loop ileostomy closure to reduce postoperative ileus: a multicenter randomized controlled trial. Colorectal Dis. 2017; 19(11): 1024-1029, doi: 10.1111/codi.13720, indexed in Pubmed: 28498636.

22. Wolff BG, Viscusi ER, Delaney $C P$, et al. Patterns of gastrointestinal recovery after bowel resection and total abdominal hysterectomy: pooled results from the placebo arms of alvimopan phase III North American clinical trials. J Am Coll Surg. 2007; 205(1):43-51, doi: 10.1016/j. jamcollsurg.2007.02.026, indexed in Pubmed: 17617331.

23. Smeets BJJ, Luyer MDP. Nutritional interventions to improve recovery from postoperative ileus. Curr Opin Clin Nutr Metab Care. 2018; 21(5): 394-398, doi: 10.1097/MCO.0000000000000494, indexed in Pubmed: 30074915.

24. Harper CM, Lyles YM. Physiology and complications of bed rest. J Am Geriatr Soc. 1988; 36(11): 1047-1054, doi: 10.1111/j.1532-5415.1988. tb04375.x, indexed in Pubmed: 3049751.

25. Kehlet $\mathrm{H}$. Multimodal approach to control postoperative pathophysiology and rehabilitation. Br J Anaesth. 1997; 78(5): 606-617, doi: 10.1093/bja/78.5.606, indexed in Pubmed: 9175983.

26. Svatek RS, Fisher MB, Williams MB, et al. Age and body mass index are independent risk factors for the development of postoperative paralytic ileus after radical cystectomy. Urology. 2010; 76(6): 1419-1424, doi: 10.1016/j.urology.2010.02.053, indexed in Pubmed: 20472264.

27. Artinyan A, Nunoo-Mensah JW, Balasubramaniam S, et al. Prolonged postoperative ileus-definition, risk factors, and predictors after surgery. World J Surg. 2008; 32(7): 1495-1500, doi: 10.1007/s00268-008-9491-2, indexed in Pubmed: 18305994.

28. Chapuis PH, Bokey L, Keshava A, et al. Risk factors for prolonged ileus after resection of colorectal cancer: an observational study of 2400 consecutive patients. Ann Surg. 2013; 257(5): 909-915, doi: 10.1097/SLA.0b013e318268a693, indexed in Pubmed: 23579542.

29. Vather $R$, Josephson $R$, Jaung $R$, et al. Development of a risk stratification system for the occurrence of prolonged postoperative ileus after colorectal surgery: a prospective risk factor analysis. Surgery. 2015; 157(4): 764-773, doi: 10.1016/j.surg.2014.12.005, indexed in Pubmed: 25724094. 